\title{
SC|AC
}

Edúcaçã̃o, Comunicação e Tecnologia

Atribuição BB CY 4.0

\section{"Ouvindo lives enquanto passo a roupa": relato de experiência de professoras universitárias durante a pandemia de COVID-19}

\section{Resumo}

Luciana Fernandes de Medeiros ${ }^{1}$

Renata Meira Veras ${ }^{2}$

Vanessa Santos de Arruda Barbosa 3

A pandemia de Covid-19 trouxe a necessidade de mudança na rotina de diversas famílias em vários países, incluindo o Brasil. O presente artigo é um relato de experiência cujo objetivo é compreender a rotina de três professoras pesquisadoras mediante a situação de pandemia. As professoras trabalham em universidades federais no Nordeste, têm a mesma faixa etária e dois filhos em idade escolar cada uma. Nos relatos foi possível identificar como está a rotina de trabalho durante a pandemia, o cuidado dos filhos e como estão se sentindo diante das discussões na universidade sobre aulas remotas. Observou-se que as professoras estão trabalhando em casa com várias atividades fragmentadas ao longo do dia. Isso tem trazido ansiedade e estresse devido à sobrecarga. Há necessidade de se refletir sobre a saúde mental das professoras universitárias que estão em situação similar.

\section{Palavras-chave}

Covid-19. Professoras universitárias. Rotina.

Recebido em: 28/07/2020

Aprovado em: 26/01/2021

\footnotetext{
${ }^{1}$ Psicóloga, doutora em psicologia social e professora adjunta do curso de Psicologia da Faculdade de Ciências da Saúde do Trairi/Facisa/UFRN. Especialista em psicologia clínica fenomenológico-existencial.

E-mail: lucianamedeirosufrn@gmail.com

${ }^{2}$ Psicóloga e Fisioterapeuta. Doutora em Psicologia pela UFRN. Professora Associada do Instituto de Humanidades, Artes e Ciências da UFBA. Docente permanente do Programa de Pós Graduação em Psicologia da UFBA. Bolsista Produtividade CNPq nível 2.

E-mail: renatameiraveras@gmail.com

${ }^{3}$ Bióloga, Professora Associada do Centro de Educação e Saúde da Universidade Federal de Campina Grande, Doutora em Ciências da Saúde pela UFRN e mestre em Biologia Parasitária pelo Instituto Oswaldo Cruz/FIOCRUZ. Pesquisadora na área de epidemiologia de doenças parasitárias e vetores.

E-mail:vambioo1@gmail.com
} 


\title{
"Listening to lives while ironing clothes": experience report of university professors during the COVID-19 pandemic
}

\begin{abstract}
The Covid-19 pandemic came up with the need to change the routine of many families in several countries, including Brazil. This article is an experience report that aims to understand the routine of three researcher stowards a pandemic situation. The professors work at federal universities in the Northeast, are in the same age range, and two school-age children each. In the reports, it was possible to identify how the work routine is during the pandemic, children care and how they are feeling when discussing about remote classes at the university. It was observed that the professors are working at home with various fragmented activities throughout the day. Such situation has brought anxiety and stress due to overtask. There is a need to reflect on the mental health of university professors who are in a similar situation.
\end{abstract}

\section{Keywords}

Covid-19. Professors. Daily routine. 


\section{Introdução}

Em março/2020, os brasileiros e as brasileiras foram surpreendidos com a pandemia do coronavírus SARS-CoV-2, causador da doença COVID-19, que começou na China em novembro/2019 e espalhou-se para 216 países (WHO, 2020). Medidas de contenção da pandemia como o distanciamento social, associadas a outras práticas higiênicas e protocolos de proteção são necessários para diminuir a incidência de casos e óbitos, uma vez que ao achatar a curva de infecção, se evita o colapso dos sistemas de saúde (Brooks et al, 2020). Nesse sentido, os estados e municípios, obedecendo normas sanitárias, publicaram decretos restringindo funcionamento de serviços, comércios, instituições públicas e estabelecimentos de ensino.Tal situação trouxe uma série de discussões no país e diversas implicações foram elencadas nos mais diversos setores. Houve um embate entre gestores que culminou em diferentes discursos: ora se defendia o lockdown (todos ficarem em casa), ora se defendia a abertura gradual de comércios e outros serviços. Isso, muito provavelmente, contribuiu para uma significativa taxa de não adesão ao distanciamento social em algumas cidades e o desgaste emocional entre cidadãos, os que defendiam e os que não defendiam o lockdown.

A situação de pandemia contribuiu para que algumas pessoas perdessem seus empregos, para que alguns profissionais liberais se vissem na iminência de mudar a forma de trabalhar para não perder sua renda, e também na volta de estudantes para suas casas. Isso sem falar nas perdas no campo da economia. Com a presença das crianças em casa, famílias inteiras precisaram se adequar a essa nova situação, não sem algumas consequências, que podem contribuir para uma série de conflitos e até aumento da violência intrafamiliar. Muitas escolas adotaram o ensino remoto e as famílias precisaram organizar uma nova rotina para as aulas online das crianças e adolescentes.

As discussões sobre educação à distância e o ensino remoto durante a pandemia também chegaram às universidades, trazendo divergências entre professores e também entre alunos. Os debates explicitam as já familiares desigualdades sociais e as consequências nefastas dos cortes recorrentes em pesquisa, ensino e 
extensão que as universidades vêm sofrendo desde 2016. Várias questões vêm surgindo com esse debate, a maioria sem respostas fáceis. De um lado, discursos que criticam o ensino remoto quando questionam se todos os estudantes têm acesso à Internet, e, se não têm, o que fazer para garantir essa inclusão. Ademais, questionam se o papel do professor universitário é apenas ministrar aulas e cumprir os créditos do projeto pedagógico. Por outro lado, tem o discurso daqueles que veem o ensino remoto como possibilidade de acesso aos estudantes que estão em casa e como uma maneira plausível, no atual momento, de não haver desmotivação entre os estudantes, que estão sem sua rotina de estudos.

Oliveira (2019) coloca a importância de compreender os contextos nos quais os alunos estão inseridos para que a aprendizagem ocorra a partir dessa contextualização. Nesse sentido, se boa parte dos alunos não têm acesso à Internet fica mais difícil propor ensino remoto. Porém, as denominadas tecnologias de informação e de comunicação (TIC) estão cada vez mais inseridas no cotidiano de todos, mesmo que a pessoa possua apenas um aparelho de celular (Oliveira, 2019). Isso mostra a importância de considerar essas possibilidades do uso de TIC no processo ensino-aprendizagem e o professor contemporâneo precisa considerar a importância de sua inserção nos seus processos de trabalho. Talvez ainda mais agora diante dessa situação de pandemia.

Observa-se que uma série de eventos foram desencadeando outros,tal como em uma avalanche. Os profissionais de saúde mental começaram a alertar sobre a possível epidemia de sintomas de ansiedade e depressão devido ao isolamento e distanciamento social, principalmente entre aqueles que já sofriam com problemas psicológicos.

É nesse contexto de incertezas, inquietudes e novidades que se insere algumas mulheres brasileiras. No caso específico do presente trabalho, professoras de universidades públicas, pesquisadoras e mães. 
O presente trabalho, portanto, consiste em um relato de experiência de três mães professoras e pesquisadoras sobre o impacto da pandemia e do distanciamento social em suas vidas cotidianas, tanto em relação ao trabalho na universidade, como em relação ao cuidado com os filhos.

\section{Procedimentos metodológicos}

Por ser um relato de experiência, o artigo em tela tomou como base o depoimento das três professoras universitárias que o assinam. Dessa maneira, não se fez necessário avaliação pelo Comitê de Ética em Pesquisa (CEP). As autoras escreveram seus depoimentos a partir de três questões: 1) como está a minha rotina de trabalho durante a pandemia de Covid-19, 2) como está sendo cuidar dos filhos e ajudá-los nesse período de aulas remotas e 3) como estou me sentindo diante das discussões na universidade em que trabalho.

Os depoimentos foram elencados e organizados segundo as temáticas e feita uma interlocução através de semelhanças e diferenças entre as experiências, valorizando, principalmente os sentimentos gerados diante dessa situação.

As três professoras têm a mesma faixa etária (entre 40 e 45 anos), trabalham com o regime de dedicação exclusiva em universidades federais, têm dois filhos em idade escolar e moram em cidades diferentes da região Nordeste.Uma das professoras é bióloga e as outras duas são psicólogas, sendo que, uma, dentre as psicólogas, também é fisioterapeuta. As três professoras estão trabalhando de forma remota desde março/2020. Os depoimentos foram tomados em julho/2020.

\section{Rotina de trabalho durante a pandemia}

Diante dessa questão da rotina de trabalho, as professoras apontam as mudanças que precisaram fazer desde o início da pandemia e da suspensão de aulas:

"Quando as aulas foram suspensas, pensei: agora tenho tempo de escrever artigos, pois com as aulas, nem sempre consigo tempo para escrever e publicar. 
Faço muita extensão com a comunidade e com os alunos e isso toma muito tempo. E realmente consegui escrever bastante. Tenho reuniões semanais do projeto PET e tenho mantido algum contato com os alunos da extensão e do estágio. Com os alunos da extensão, tenho incentivado as leituras e escrita de artigos, mas nem todos estão motivados. Mas, aí vieram as discussões sobre ensino remoto e isso me deixou muito desgastada emocionalmente.(...) Dia desses, eu me vi varrendo a casa enquanto ouvia uma live sobre ensino remoto. Outro dia, me vi passando roupa enquanto ouvia uma entrevista com professores da educação. Também já organizei o almoço das crianças enquanto ouvia uma reunião. Sim, porque com a pandemia, eu e meu marido assumimos todo o serviço doméstico. E á, precisamos cuidar da casa todos os dias, revezando com as reuniões e outras atividades do nosso trabalho. É difícil porque não sei cozinhar e o trabalho doméstico toma tempo!”. (professora 01)

"Não estou tendo exatamente uma rotina de trabalho como eu gostaria, como eu tenho quando estou na universidade. Não estou tendo regularidade de horários, principalmente devido aos trabalhos domésticos e aulas online das crianças,que preciso dar o suporte. Como pedi a minha funcionária que ficasse em casa nesse período, acabei por absorver muitas tarefas domésticas, ainda que haja colaboração das outras pessoas da casa. Tenho tido muitas demandas, pois continuo com as minhas pesquisas, escrevendo artigos, sou orientadora de iniciação científica, de TCC, fazendo capacitações e ainda tenho cargo administrativo. Então, preciso trabalhar, cumprir prazos e me concentrar no trabalho e muitas vezes eu interrompo essas atividades, com frequência para atender alguém de casa. Além de duas crianças, tenho meus pais idosos que vieram morar comigo e um marido que também é grupo de risco. Nesse caso só eu da casa posso sair para resolver alguma coisa ou providenciar alguma necessidade de alguém da família, pois estamos seguindo rigorosamente as normas sanitárias de isolamento. Interrompo o trabalho para receber as compras, higienizar tudo, atender a criança que precisa entrar na sala virtual, pegar algum material, preparar lanche, fazer tarefas escolares ... necessidades das mais variadas, que não teria com as crianças na escola e com uma funcionária em casa. Isso tudo gera cansaço, estresse e ansiedade, pois demoro a voltar a me concentrar e executar as tarefas do trabalho. $\mathrm{O}$ ambiente 
doméstico traz múltiplas interferências, pois são muitas pessoas circulando pelos cômodos, barulhos, etc. Embora me considere uma pessoa calma, às vezes me vejo irritada com isso tudo e frequentemente minhas atividades da universidade se estendem até altas horas da noite, dependendo dos prazos que preciso cumprir. Por conta disso acho, e acredito que por toda essa exposição a telas, tenho tido bastante insônia e uma dificuldade para desligar o cérebro, acordando cansada no dia seguinte. Toda essa mudança tem interferido também no meu autocuidado, eu estou tendo pouco tempo para fazer atividades físicas, ver um filme, ler um livro ... esse tempo não está me sobrando muito.” (professora 2).

"Dois dias após o início do isolamento decretado na cidade de Salvador, Bahia, em meados de março, nos mudamos para zona rural no interior do Estado (280 $\mathrm{km}$ de Salvador) onde a família do meu marido tem uma fazenda. Nos primeiros dias fiquei bastante atenta às redes sociais na esperança que esse isolamento durasse uns quinze a vinte dias. Não tinha a dimensão da capacidade de propagação e letalidade do COVID19! Após quinze dias, a escola dos meus filhos deu início às aulas remotas e me deparei com uma nova atividade: ser tutora de educação remota. Como a UFBA estava com as atividades suspensas, passei a fazer caminhadas (trilhas), ler livros técnicos e romances e realizar a limpeza da casa no turno da manhã e, no turno da tarde, a missão era auxiliar nas tarefas de casa dos filhos e acompanhá-los nas aulas remotas. Isso levava a tarde inteira. Essa adaptação levou cerca de 60 dias. $O$ mais difícil foi percebermos que não estávamos de férias (por ser esse o local onde passamos as férias). Após esse tempo, a UFBA retomou algumas atividades como reuniões de colegiados e congregação, reuniões de Núcleo Docente Estruturante. A partir de então, além de participar de tais reuniões, também retomei as atividades de orientação, passei a acompanhar palestras acerca do meu tema de pesquisa disponíveis no Youtube e enfatizei a escrita dos artigos. Eu sou bolsista produtividade em pesquisa do CNPq e tenho como meta manter esse auxílio. Consegui me adaptar a trabalhar ao lado do meu filho mais velho enquanto ele está em aula remota e assim continuo com a produção em dia. Conto também com o auxílio de mestrandos que estão bem engajados com os produtos das nossas pesquisas. Continuo acompanhando os noticiários sobre o COVID-19, mas já não tenho 
mais tanta esperança de retorno esse ano das atividades presenciais." (professora 03)

Observa-se nesses relatos que as três professoras precisaram se adaptar à rotina de trabalhar em casa com a presença dos filhos e de outros moradores da casa. Isso tem gerado um significativo grau de interrupção durante o processo de produção e criação intelectual, tão necessários para uma professora/pesquisadora. Além das demandas das pessoas que moram na casa, há também a necessidade de realização das tarefas domésticas. Observa-se uma sobrecarga significativa no sentido de, além de precisar continuar produzindo durante a pandemia, ainda precisam dar conta das novas necessidades que surgiram com essa mudança no cotidiano. Há também uma necessidade de se reinventar, pensar novas possibilidades para as atividades interrompidas:

"Fazer pesquisa, nesse momento, é complicado porque não temos como entrevistar as pessoas de forma presencial. A pesquisa que está em andamento, coordenada por mim, não tem nada a ver com a pandemia e exige presença dos estudantes no local. Então, estamos parados. Incentivei a produção de artigos teóricos e/ou relatos de experiência, mas nem todos estão motivados. Não me sinto cobrada a produzir, mas por gostar de escrever, sinto sempre essa motivação de escrever algo, de contribuir com a construção do conhecimento. Porque eu gosto de fazer, não significa que consigo publicar muito. As revistas têm muitas exigências nas normatizações e isso me desanima um pouco. Além disso, sempre me envolvo muito com extensão e ensino, o que sobra menos tempo para a pesquisa”. (professora 01)

Esses relatos mostram que, mesmo diante de uma situação de pandemia, as professoras adaptaram suas atividades intelectuais para o ambiente doméstico. Ou seja, continuam desenvolvendo artigos, pesquisas e participando de reuniões on-line, enquanto os filhos assistem aula. Somou-se a isso a necessidade de realizar os trabalhos domésticos. O impacto da pandemia entre essas professoras, e em muitas outras, talvez nem seja na produtividade, mas em sua saúde mental. Isso porque elas fazem várias coisas ao mesmo tempo, não estão 
dormindo bem e podem ter sintomas de ansiedade em função de desejarem dar conta de todas as demandas que aparecem concomitantemente.

\section{O cuidado com os filhos}

As professoras comentam sobre a rotina com os filhos em casa:

"Minha maior lástima com relação aos meus filhos (um menino de 14 anos e uma menina de oito) é saber que eles estão perdendo um pouco com a falta de interação na escola, estão isolados, em casa, sem esportes e sem toda a riqueza de experiências interpessoais que a escola oferece. Além disso, eles não estão gostando das aulas online, mas eu procuro incentivá-los a aproveitar o que temos no momento. $\mathrm{E}$ a agradecer, porque eles estão numa boa escola, em uma situação relativamente boa. O que me acontece muito comumente, nesse cotidiano em casa, é estar em reuniões online e meus filhos chegarem com demandas. Isso me tira a atenção da reunião e, às vezes, preciso interromper minha atividade para resolver a demanda naquele momento, ou, responder para eles que esperem porque não posso parar. Já me peguei várias vezes tentando prestar atenção neles e na atividade, ao mesmo tempo, e isso traz muita ansiedade para mim. Como se eu quisesse estar em dois lugares concomitantemente. É impossível, mas me vejo nessa situação. É muito louco isso!" (professora 01).

“(...) Esse tempo quando me sobra eu procuro dar mais atenção para as crianças, que já não tem coleguinhas e não estão com vida social. Procuro brincar, conversar, ou quando estou muito cansada, apenas deitar na cama com eles (...). Procuro dar o suporte nas tarefas da escola e do curso de inglês e preciso ficar atenta aos prazos da escola também. Sempre centralizei as atividades escolares das crianças em mim e confesso que já esqueci algumas atividades. Estou no processo de aprender a compartilhar essa responsabilidade com meu marido, embora as crianças tenham uma certa resistência. Minha filha diz que meu trabalho é eterno, não termina nunca, isso porque não consigo manter o fluxo de ideias para concluir as atividades dentro de horários determinados. $\mathrm{E}$ isso é uma coisa que está me estressando bastante e tá me 
dando a sensação de que embora esteja trabalhando estou sendo pouco produtiva" (professora 02).

"Eu estou residindo atualmente na fazenda que é o local onde passamos as férias. Então foi uma adaptação difícil entender que apesar de estarmos no local de férias, devíamos continuar com os afazeres cotidianos da cidade. Em relação aos cuidados com a casa, confesso que é bem mais tranquilo estar na fazenda do que no apartamento em Salvador. Na cidade, eu teria dispensado a diarista que ia duas vezes por semana e assumiria os afazeres da casa. Mesmo tendo um marido bem participativo, certamente eu acabaria assumindo a maior parte das tarefas domésticas porque ele trabalha na fazenda e viaja toda semana. Assim, unimos o útil ao agradável, já que ele trabalha na fazenda. Na fazenda temos uma caseira que cozinha as refeições e lava as roupas, então fico responsável apenas pela limpeza da casa. Tenho dois filhos, um de oito anos que está no terceiro ano e o outro de seis anos que está no grupo 5 , no próximo ano ele irá para o primeiro ano. Descobri nessa quarentena que meu filho mais velho tem uma certa dificuldade de atenção/concentração. Então, fazer atividade de casa e acompanha-lo nas aulas remotas passou a ser um desafio enorme para ele e para mim, principalmente porque as aulas remotas duram cerca de duas horas. Além disso, sendo a escola dos meninos construtivista, tive de dar conta de ensinar assuntos a partir de novas metodologias como adição e subtração (com reserva) por decomposição. Saí da "conta armada" para uma nova perspectiva de fazer cálculos. Ou seja, reaprendi a fazer contas. E me dei conta do quanto foi importante aprender outras maneiras de enxergar os números. Passo a pensar como podemos mudar a forma de ver o mundo também. Em relação ao mais novo, as atividades são mais iniciais e não demandam tanto esforço. Como meu marido trabalha na fazenda, eu assumo integralmente as atividades escolares das crianças e isso demanda esforço cognitivo e tempo". (professora 03).

Para as professoras, tem sido um desafio acompanhar os filhos em sua rotina de aulas remotas seja porque alguns não gostam, seja porque identificam novas demandas com essa situação. Mesmo os pais participando das atividades domésticas, percebe-se uma carga maior sobre as mulheres em relação às demandas escolares dos filhos. O dia a dia dessas professoras parece uma 
miscelânea de atividades fragmentadas. O tempo organizado para uma reunião ou leitura pode ser muito bem interrompido por uma demanda doméstica ou das crianças. É muito angustiante ter que se dividir em várias tarefas ao mesmo tempo.

\section{Sentimentos diante das discussões atuais nas universidades}

Como se não bastasse a situação de pandemia e o significativo número de tarefas que se revezam de forma desorganizada no dia a dia, as professoras ainda precisam lidar com os debates sobre a retomada das aulas no formato remoto. Isso porque, decorridos quatro meses de suspensão de aulas, o percurso da pandemia no Brasil não tem dado segurança suficiente para que estudantes e professores voltem às salas de aula.

"Quando as discussões sobre ensino remoto começaram na universidade, eu não fui tão pega de surpresa porque já esperava algo do gênero. A pandemia está demorando muito e não vai ser possível passar um ano inteiro sem aulas, alunos precisam concluir seus cursos, outros, precisam entrar na universidade e outros precisam da motivação de uma rotina de estudos. Mas, tal mudança traz muitas implicações, entre elas, o acesso à Internet por parte de alguns estudantes. As discussões foram bem desgastantes e o que deu para perceber foi que a incerteza do tempo que ficaremos no distanciamento social traz a possibilidade do ensino remoto, mas também mostra as limitações do acesso. O que fazer diante de tudo isso, então? São muitas perguntas e poucas respostas. Apesar de tudo, comecei a me preparar para aulas remotas, vi aí uma possibilidade de aprender algo novo e experimentar novas formas de aprender e ensinar" (professora 01).

"Sobre as discussões das aulas remotas e construção de uma resolução na universidade, ocorreram inúmeras reuniões em várias instâncias e também lives, na qual procurei assistir e analisar os vários pontos de vista. Entendo toda a necessidade dos alunos que estão em processo de vulnerabilidade, que não tem acesso, rede, condições econômicas e entendo que a aula remota pode ser um mecanismo excludente, me preocupa o amparo aos mais vulneráveis, mas por outro lado tem-se a necessidade de outros alunos, principalmente os 
concluintes. Temos ainda toda a pressão da sociedade e governo para darmos uma resposta no quesito ensino, que é o mais visível, já que pesquisa, extensão e as atividades administrativas continuam na universidade. Com todo esse cenário de insegurança sanitária e de não sabermos quando voltaremos à presencialidade, penso que teríamos mesmo que ofertar aulas remotas de maneira extraordinária. Ao mesmo tempo, eu me sinto insegura, embora eu já tenha feito algumas capacitações, de mudar bruscamente de metodologia, principalmente por não dominar totalmente as tecnologias. Mas entendo que o aprendizado se dará na prática e vejo também como uma oportunidade de aprendizado". (professora 02)

"As discussões na UFBA acerca das atividades iniciaram 60 dias depois do início da quarentena. Basicamente estamos reestruturando a passagem do modelo de ciclos (Bacharelado Interdisciplinar em Saúde) para os cursos de progressão linear. Então, as reuniões de colegiado estão sendo mais voltadas para construir propostas de mudanças do sistema vigente. Não nos debruçamos especificamente sobre o tema retomada remota ou não das atividades. Em reunião de congregação com todos os professores do instituto, o reitor participou e demonstrou preocupação na retomada remota das atividades, já que poderia aumentar a desigualdade dentro da universidade. Foi realizada uma pesquisa no início da quarentena que indicou que a maior parte de estudantes de baixa renda não possui boa internet ou computador para participar das atividades. No entanto, após essa reunião o reitor já fez algumas declarações da possibilidade de retorno remoto. Somos um grupo bem homogêneo e não houve grandes conflitos em relação a essa decisão, se vier a ser tomada. A maioria não se opôs ao planejamento de retorno. Como temos grande parte das disciplinas teóricas, não veria grandes problemas no retorno remoto e penso que é uma ideia compartilhada pelos colegas. Certamente levarei algumas semanas para me adaptar aos recursos tecnológicos disponibilizados para essa tarefa. Mas é um caminho possível mediante a situação emergencial pela qual ainda passamos e a maioria das universidades em todo o mundo está se organizando para esse modelo". (professora 03). 
Novos tempos, novas necessidades surgem. Quem diria que um dia seria possível ministrar aulas de forma remota, uma vez que o ensino presencial não contribui somente para a construção do conhecimento, mas também para o desenvolvimento de competências e habilidades interpessoais e de afetividade. Mas, eis que chegou uma pandemia para sacolejar esse mundo consolidado e fazer pensar outras possibilidades de ensino.

Nos relatos acima, fica evidente que as professoras se deparam com esse novo incerto que é o sucesso (ou não) das aulas remotas em virtude da impossibilidade da presencialidade. A professora 01 tem sofrido com os debates o que é uma angústia a mais em sua já fragmentada rotina de trabalho/cuidado com os filhos/ serviços domésticos. Já as outras professoras não apresentam tanto desgaste nesse tema, talvez porque seu grupo de trabalho tenha uma visão mais parecida com a delas. São desafios que se impõem de maneira muito rápida e que demanda abertura, flexibilidade, criatividade e resiliência.

Os relatos das professoras indicam a dificuldade em se adaptar a essa nova realidade imposta pelo COVID-19. No campo profissional, além das demandas de pesquisa como escrita de artigos e orientações de estudantes, somam-se as burocráticas que envolvem a participação em reuniões, planejamentos, etc. E no campo pessoal, há crianças em tempo integral em casa, serviços domésticos (nem sempre totalmente compartilhadas pelos companheiros) e o auxílio pedagógico aos filhos. Velho (2006) problematiza essa questão ao afirmar que a inserção das mulheres na ciência está baseada numa cultura baseada no modelo masculino de carreira. Esse modelo envolve compromissos de tempo integral para o trabalho, produtividade em pesquisa, relações competitivas que condizem ao perfil masculino, restringindo e direcionando a participação das mulheres nesse contexto.

“Apesar de estar trabalhando todos os dias na escrita de algum material, na coordenação da residência, no projeto do PET e nos projetos de extensão, já escutei de amigos que estou numa vida muito boa porque, na cabeça deles, estou em casa só escolhendo a comida delivery e esperando o próximo lançamento do Netflix. Isso dói porque parece que estou fazendo nada e que sou inútil para a 
sociedade. Entendo que minha situação é melhor do que muitos outros, mas isso não significa que não esteja sofrendo de alguma forma. Tenho dificuldade para dormir todos os dias, tenho sintomas frequentes de ansiedade, como dores de cabeça, tonturas e falta de ar. Essa ansiedade vem da necessidade de mudança, do desconhecido, da incerteza, do medo de adoecer e de ver pessoas queridas doentes. Já perdi um amigo pro Covid-19. Tenho outros que estão na linha de frente. Mesmo numa situação boa, por estar podendo trabalhar em casa, não significa que não tenho meus sofrimentos" (professora 01).

"Tem dias que estou bem ansiosa em relação às notícias sobre retomadas das atividades (tanto presenciais quanto remotas). Pensar que as atividades poderão retomadas integralmente de modo remoto até o final do ano me causa um desconforto duplo: tanto pelas auto-cobranças em relação ao engajamento dos meus estudantes da UFBA, quanto ao avanço na aprendizagem por parte dos meus filhos, uma vez que estou me sentindo muito mais responsável pela escolarização deles." (professora 03).

Não é fácil para as mulheres seguirem uma carreira numa sociedade que ainda se mostra patriarcal, situando-as como principais responsáveis pelos cuidados da casa e dos filhos. E ainda mais grave é que, apesar de todo o esforço e dedicação, tendem a ser vistas como alienadas, frágeis, e tendo uma "vida boa", uma vez que muitos acham que estão de folga todos os dias da semana por estarem em casa devido à pandemia.

\section{Considerações Finais}

Os relatos apontam que as professoras estão bastante ativas em suas atividades laborais desde o início da pandemia e que novas demandas surgem a cada dia, sendo um desafio constante para elas. Participar de reuniões online enquanto varrem a casa, assistir lives enquanto passam roupa, escrever artigos enquanto auxiliam os filhos nas aulas remotas, pensar as readequações necessárias em seus projetos de pesquisa e extensão tem sido uma constante nessa rotina de pandemia. 
Tal situação com certeza pode trazer um impacto na produtividade dessas professoras. Mesmo assim, a participação das mulheres continua crescente nessa profissão, assim como na obtenção de bolsas de produtividade. Talvez o alto preço a pagar seja a repercussão dessas questões na saúde mental, levando também a índices cada vez maiores de transtornos mentais em mulheres.

Nesse sentido, de que vale a pena ter uma alta produtividade se haverá perda significativa na saúde mental? Faz-se necessário, portanto, repensar essas exigências, reconhecer o valor do trabalho doméstico e do cuidado com os filhos e valorizar cada artigo escrito, cada aula ministrada como uma vitória diante de tantas demandas. Além disso, é preciso também abrir espaço para o cuidado de si, seja através de atividades físicas regulares, terapia, hobbies e outras ações que promovam saúde mental.

\section{Referências}

BROOKS, S. K.; WEBSTER, R. K.; SMITH, L. E.; WOODLAND, L.; WESSELY, S.; GREENBERG, N.;\& RUBIN, G. J. The psychological impact of quarantine and how to reduce it: rapid review of the evidence. The Lancet, VOLUME 395, ISSUE 10227, P912-920, MARCH 14, 2020

OLIVEIRA, Maria Elizete Melo. Quebrando paradigmas: a educação em meio às tecnologias. SCIAS Edu., Com., Belo Horizonte, v.1, n.1, p.62-78, 2019.

VELHO, L. Prefácio. In: SANTOS, L. W.; ICHIKAWA, E. Y.; CARGANO, D. F. (Orgs.). Ciência, tecnologia e gênero: desvelando o feminino na construção do conhecimento.Londrina: IAPAR, 2006. p. xiii-xviii.

WORLD HEALTH ORGANIZATION (WHO).Coronavirus disease (COVID-19) pandemic. Disponível em: https://www.who.int/emergencies/diseases/novelcoronavirus-2019. Acesso em 21/07/2020. 